\title{
Short-term serial assessment of electronic patient-reported outcome for depression and anxiety in breast Cancer
}

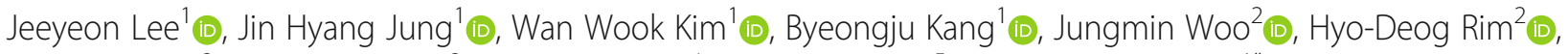

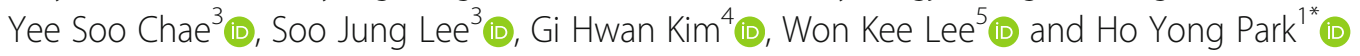

\begin{abstract}
Purpose: The incidence of depression and anxiety is higher in patients with breast cancer than in the general population. We evaluated the degree of depression and anxiety and investigated the changes in patients with breast cancer during the treatment period and short-term follow-up period.

Methods: Overall, 137 patients with breast cancer were evaluated using the Patient Health Questionnaire 9-item depression scale (PHQ-9) and Generalized Anxiety Disorder scale (GAD-7). The scales were developed as a webbased electronic patient-reported outcome measure, and serial results were assessed before the operation, after the operation, in the post-treatment period, and in the 6-month follow-up period after surgery.

Results: The degree of depression and anxiety increased during treatment and decreased at 6-month follow-up, even if there were no statistical differences among the four periods (PHQ-9: $p=0.128$; GAD-7: $p=0.786$ ). However, daily fatigue (PHQ-9 Q4) and insomnia (PHQ-9 Q3) were the most serious problems encountered during treatment and at 6-month follow-up, respectively. In the GAD-7, worrying too much (Q3) consistently showed the highest scores during the treatment and follow-up periods. Of the patients, 7 (5.11\%) and 11 (8.03\%) patients had a worsened state of depression and anxiety, respectively, after treatment compared with before treatment.

Conclusion: Most factors associated with depression and anxiety improved after treatment. However, factors such as insomnia and worrying too much still disturbed patients with breast cancer, even at 6-month follow-up. Therefore, serial assessment of depression and anxiety is necessary for such patients.
\end{abstract}

Keywords: Breast cancer, Depression, Anxiety, Serial assessment

\section{Introduction}

Breast cancer is the most common malignancy in middleaged Korean women; it is more frequently associated with depression and anxiety than other malignancies [1-4]. Physicians and patients believe that their mental stress would spontaneously improve after the treatment is

\footnotetext{
* Correspondence: phy123@knu.ac.kr

'Department of Surgery, School of Medicine, Kyungpook National University, Kyungpook National University Chilgok Hospital, Daegu 41404, Republic of Korea

Full list of author information is available at the end of the article
}

finished; however, mental status should be managed actively because poor mental health may negatively affect patient compliance and tumor prognosis $[5,6]$.

Recently, the psycho-oncological therapeutic approach has become an essential tool in the care of cancer survivors, and there has been much interest in the quality of life and mental health of cancer survivors [7]. Although a previous study reported that depression and anxiety improve with time after the diagnosis of breast cancer, no serial study related to the treatment periods of breast cancer has been conducted [8]. Therefore, it is difficult

(c) The Author(s). 2021 Open Access This article is licensed under a Creative Commons Attribution 4.0 International License, which permits use, sharing, adaptation, distribution and reproduction in any medium or format, as long as you give appropriate credit to the original author(s) and the source, provide a link to the Creative Commons licence, and indicate if changes were made. The images or other third party material in this article are included in the article's Creative Commons licence, unless indicated otherwise in a credit line to the material. If material is not included in the article's Creative Commons licence and your intended use is not permitted by statutory regulation or exceeds the permitted use, you will need to obtain permission directly from the copyright holder. To view a copy of this licence, visit http://creativecommons.org/licenses/by/4.0/. The Creative Commons Public Domain Dedication waiver (http://creativecommons.org/publicdomain/zero/1.0/) applies to the data made available in this article, unless otherwise stated in a credit line to the data. 
to predict at what point physicians should intervene to improve the patient's mental health.

The patient-reported outcome (PRO) plays a crucial role in the assessment of the patient's own health and is the best way to obtain an accurate assessment [9]. Because it is important that a serial assessment be easily accessible, the use of an electronic PRO (ePRO) platform, such as a web-based or smartphone-based application, is preferred in younger generation. Furthermore, the use of an ePRO can minimize the time spent for statistical analysis and maximize the number of responders with early intervention.

The authors evaluated the degree of and observed changes in anxiety and depressive symptoms throughout the preoperative, postoperative, post-treatment, and 6month follow-up periods using the ePRO-based Patient Health Questionnaire 9-item depression scale (PHQ-9) and Generalized Anxiety Disorder scale (GAD-7) to figure out the candidates who may need a psychotherapeutic management $[10,11]$.

\section{Methods}

Authors from the breast cancer center of Kyungpook National University Chilgok Hospital (KNUCH, Daegu, Republic of Korea) designed the SAAD trial (Serial Assessment of Anxiety and Depressive symptoms in breast cancer), which is a prospective, questionnaire-based serial cohort study. The ePRO platform was developed, and archived data was analyzed by Clupea, Inc. (epro.clupea. $\mathrm{kr}$ ) to evaluate depressive and anxiety symptoms of patients with breast cancer.

Because depressive mood and anxiety may become worse with the operation date approaching, the first examination was performed on the first day of visit to our center, and the postoperative examination was performed during the hospitalization period within 1 week after operation. However, the survey was not conducted immediately after surgery because postoperative pain would affect the results. Moreover, post-treatment examinations were conducted at the visit to the breast clinic after completion of chemotherapy or radiation and at 6-month follow-up examination after the surgery on the day of checking results of regular surveillance.

The study was conducted from January to December 2020, and all procedures in this study involving human participants were performed in accordance with the ethical standards of the Institutional Review Board of the KNUCH (KNUCH 2020-06-029-001). All enrolled patients signed the informed consent.

\section{Patients}

In total, 182 patients were diagnosed with operable breast cancer between January and April 2020. Among them, 12 patients refused to participate in the study, and
33 patients did not complete the survey for four times during the treatment and follow-up period. Eventually, 137 patients with breast cancer who had received surgery and additional treatment at $\mathrm{KNUCH}$ were included in this study. Patients were administered an electronic survey four times: preoperative, postoperative, posttreatment (after finishing adjuvant treatment, except for hormone treatment), and at 6-month follow-up from surgery. When patients were diagnosed with depression or anxiety disorder by a psychiatrist before the diagnosis of breast cancer, they were excluded from the study owing to potential different effects.

When the physician created a patients' list on the webbased system, a secured login was activated using the patients' ID numbers and names. Patients logged in using personal computer, tablet, or their own smartphone. The patients clicked the answers by themselves, and the total scores of the PHQ-9 and GAD-7 were shown after completion of the questionnaires. The physicians checked the mental status of patients in real time.

Medical records were reviewed to determine clinical and pathological factors, including age, body mass index, menstruation, marital status, childbearing status, family history of breast or ovarian cancer, and history of hormone replacement therapy as well as clinicopathological characteristics, including clinical and pathologic tumor size, axillary lymph node status, tumor subtype, adjuvant treatment, and type of surgery.

\section{Depression and anxiety disorder scale}

The ePRO was constructed based on the PHQ-9 and GAD-7. We compared and analyzed the changes in total scores and the scores for each question on the PHQ-9 and GAD-7.

The self-administrated PHQ is a standard scale that assesses several psychiatric disorders, including depressive disorder, panic disorder, anxiety disorder, bulimia nervosa, and other minor disorders (5-8). However, the brief form of the PHQ with the nine-item depression module, the socalled PHQ-9, is generally used to screen for depression [12-16]. The total score of the PHQ-9 ranges from 0 to 27 , and the level of depression severity can be classified as 0-4 (no or minimal depressive symptoms), 5-9 (mild depressive symptoms), 10-19 (moderate depressive symptoms), and 20-27 (severe depressive symptoms).

Anxiety symptoms were measured using the GAD-7, a self-administrated questionnaire, which comprises seven brief items [17-19]. Each item is scored 0 (not at all) to 3 (nearly every day), and the threshold points of mild, moderate, and severe anxiety are 5,10 , and 15 , respectively.

\section{Development of the ePRO}

The ePRO program was created to measure the depression and anxiety scale before and after treatment for 
Table 1 Clinicopathological characteristics of patients with breast cancer

\begin{tabular}{|c|c|}
\hline & $n=137$ \\
\hline Age (mean $\pm S D$, years) & $53.83 \pm 11.6$ \\
\hline Body mass index (mean $\left.\pm \mathrm{SD}, \mathrm{kg} / \mathrm{m}^{2}\right)$ & $24.82 \pm 7.25$ \\
\hline Age of menarche (mean $\pm S D$, years) & $18.81 \pm 0.71$ \\
\hline Postmenopausal status & $65(47.45)$ \\
\hline \multicolumn{2}{|l|}{ Marital status } \\
\hline Married & $106(77.37)$ \\
\hline Single & $25(18.25)$ \\
\hline Divorced & $6(4.38)$ \\
\hline \multicolumn{2}{|l|}{ Number of children } \\
\hline 0 & $16(11.68)$ \\
\hline 1 & $18(13.14)$ \\
\hline 2 & $73(53.28)$ \\
\hline$>3$ & $30(21.90)$ \\
\hline Family history of breast or ovarian cancer & $6(4.38)$ \\
\hline \multicolumn{2}{|l|}{ History of hormone replacement therapy } \\
\hline No & $134(97.81)$ \\
\hline Yes & $3(2.19)$ \\
\hline \multicolumn{2}{|l|}{ Location of tumor } \\
\hline Right & $76(55.48)$ \\
\hline Left & $61(44.53)$ \\
\hline \multicolumn{2}{|l|}{ Types of tumor } \\
\hline Ductal carcinoma in situ & $21(15.33)$ \\
\hline Invasive ductal carcinoma & $112(81.76)$ \\
\hline Invasive lobular carcinoma & $1(0.73)$ \\
\hline Other & $3(2.19)$ \\
\hline \multicolumn{2}{|l|}{ Pathologic stage } \\
\hline 0 & $22(16.06)$ \\
\hline IA & $66(48.18)$ \\
\hline$\| \mathrm{A}$ & $25(18.25)$ \\
\hline$\| \mathrm{B}$ & $15(10.95)$ \\
\hline$\| \mathrm{A}$ & $7(5.11)$ \\
\hline IIIC & $2(1.46)$ \\
\hline \multicolumn{2}{|l|}{ Estrogen receptor } \\
\hline Positive & $119(86.87)$ \\
\hline Negative & $18(13.14)$ \\
\hline \multicolumn{2}{|l|}{ Progesterone receptor } \\
\hline Positive & $102(74.46)$ \\
\hline Negative & $35(25.55)$ \\
\hline \multicolumn{2}{|l|}{ Her2/neu gene } \\
\hline Positive & $24(17.52)$ \\
\hline Negative & $113(82.49)$ \\
\hline Triple negative breast cancer & $17(12.41)$ \\
\hline Ki67 index & \\
\hline
\end{tabular}

Table 1 Clinicopathological characteristics of patients with breast cancer (Continued)

\begin{tabular}{ll}
\hline & $\boldsymbol{n}=137$ \\
\hline$<15 \%$ & $100(73.00)$ \\
Type of breast surgery & $37(27.01)$ \\
Breast conserving surgery & \\
Mastectomy & $98(71.54)$ \\
Breast reconstruction & $39(28.47)$ \\
Type of axillary surgery & $42(30.66)$ \\
No operation & \\
Sentinel lymph nodes biopsy & $4(2.92)$ \\
Axillary lymph nodes dissection & $119(86.87)$ \\
Adjuvant chemotherapy & $14(10.22)$ \\
Adjuvant radiotherapy & $62(45.26)$ \\
Adjuvant hormonal therapy & $97(70.81)$ \\
Follow-up period (mean \pm SD, months) & $93(67.89)$ \\
\hline${ }^{*}$ Data are expressed as $n$, \% & $8.01 \pm 0.69$ \\
\hline
\end{tabular}

patients with breast cancer (Supplementary figure 1). The PHQ-9 and GAD-7 were used as tools to evaluate symptoms of depression and anxiety, and the questionnaire was developed as a web-based platform considering the user's convenience (Supplementary figure 2).

After logging in to the main web page for the first time, the examiner activates the patient's name with brief clinical information to reduce the inconvenience. When the questionnaire is completed, the inspectors can check the results of each question, and serial results are archived. The severity of each item in the PHQ-9 and GAD-7 is expressed in the degree of green and pink colors, respectively (Fig. 2). In addition, to enable the examiner to detect abnormalities at a glance, severity is expressed as follows: no bar $=$ no depression (total PHQ9 score 0-4); light green bar = mild depression (total PHQ-9 score 5-9); green bar = moderate depression (total PHQ-9 score 10-19); dark green bar $=$ severe depression (total PHQ-9 score 20-27); no bar = no anxiety (total GAD-7 score 0-4); light pink bar = mild anxiety (total GAD-7 score 5-9); pink bar = moderate anxiety (total GAD-7 score 10-14); and hot pink bar = severe anxiety (total GAD-7 score 15-21).

The correlation graphs between depression and anxiety were obtained as a quartile, a one-dimensional correlation, and a heat map-style graph (Supplementary figure 3). Changes in the degree of depression and anxiety were defined as either "improved" or "worsened."

\section{Statistical analysis}

The mean scores of PHQ-9 and GAD-7 scales were compared based on the results of test which were 
conducted before surgery (preoperative), after surgery (postoperative), after adjuvant treatment (post-treatment) except hormone treatment, and at the 6-month follow-up. In addition, each questionnaire items were analyzed and compared, and the changes in the degree of depression and anxiety were analyzed.

The significance of the mean difference among the four groups was tested through repeated measures of ANOVA, and if it was significant, post hoc comparison between the two groups was performed using the Bonferroni correction after obtaining the significance probability with the least-squares mean method.

\section{Results}

The mean age of the 137 patients was 53.83 years $(\mathrm{SD}, \pm$ 11.6 years), and the mean body mass index was $24.82 \mathrm{~kg} /$ $\mathrm{m}^{2}$ (SD, \pm 7.25 ). The mean age at menarche was 15.09 years $(\mathrm{SD}, \pm 3.25)$, and 65 patients $(47.45 \%)$ were in the postmenopausal state. Overall, 106 patients (77.37\%) were married, 25 patients $(18.25 \%)$ were single, and 6 patients $(4.38 \%)$ were divorced. Sixteen patients (11.68\%) did not have a child, and 30 patients $(21.90 \%)$ had $>3$ children.

Patients underwent breast-conserving surgery $(n=98$; $71.54 \%)$ or mastectomy $(n=39 ; 28.47 \%)$, and 42 patients
(30.66\%) received immediate breast reconstruction. More than $70 \%$ of patients had early breast cancer (less than stage I), and $>80 \%$ of patients had hormonepositive breast cancer. Sixty-two patients $(45.26 \%)$ and 97 patients (70.81\%) received adjuvant chemotherapy and radiotherapy, respectively (Table 1 ).

The mean scores of both the PHQ-9 and GAD-7 increased during treatments, including surgery and adjuvant treatments, and the scores decreased at the time of the 6-month follow-up period compared with during the treatment period (Fig. 1). The mean score of PHQ-9 significantly decreased at the 6-month follow-up period compared with those in the postoperative and posttreatment periods $(p<0.0001)$, and the mean score of GAD-7 significantly decreased at the 6-month follow-up period compared with that in the post-treatment period $(p<0.0001)$.

However, the mean scores of each item were different according to the content of the questions. For the PHQ9, daily fatigue (PHQ-9 Q4) was the most serious problem encountered during the treatment period, whereas the largest number of patients complained about insomnia (PHQ-9 Q3) and second largest number of patients complained about being fidgety or restless (PHQ-9 Q8) at 6 months after the operation. For the GAD-7,

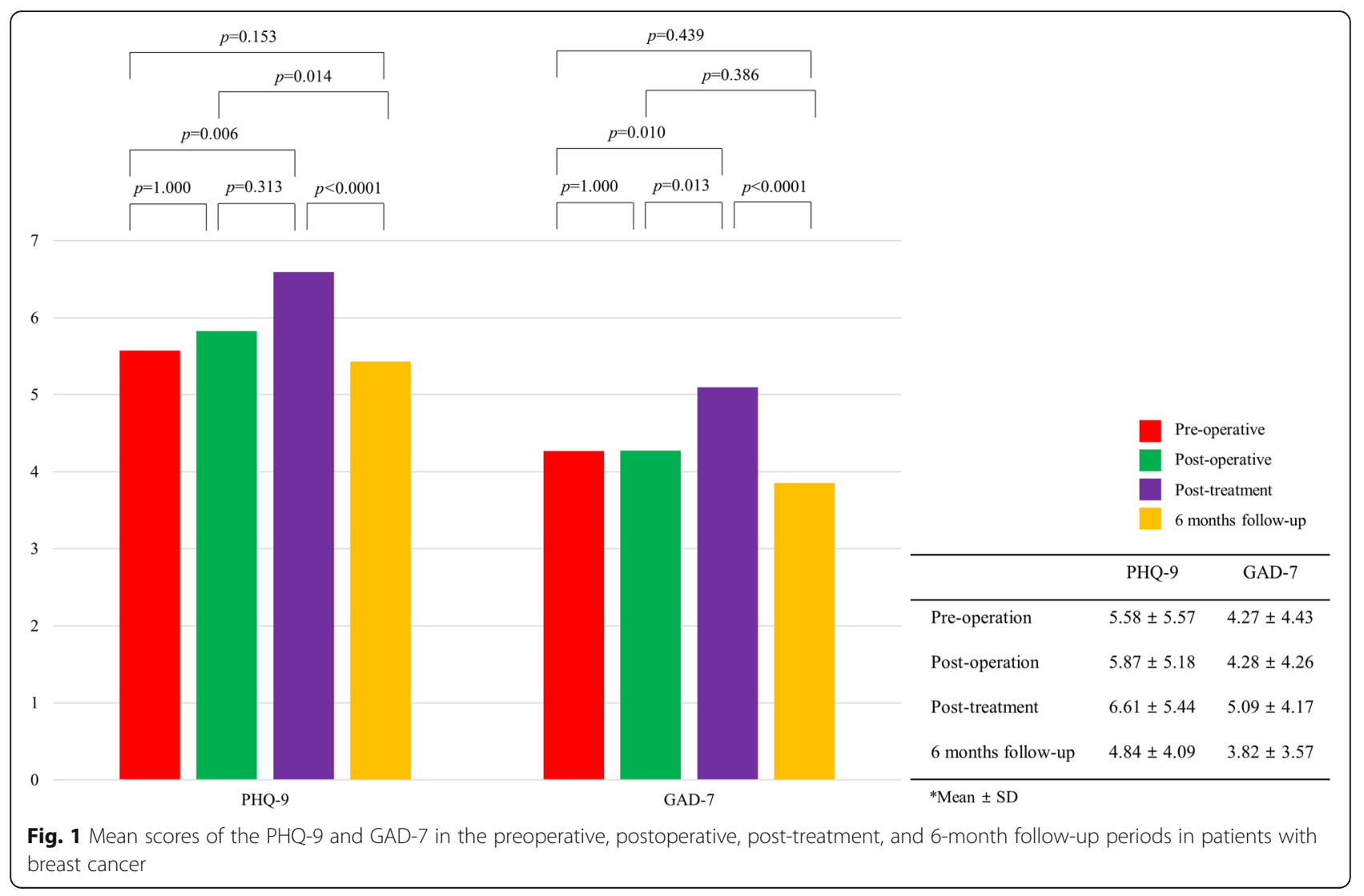


worrying too much (GAD-7 Q3) consistently showed the highest scores during the treatment and follow-up periods (Fig. 2). However, there were no statistical differences among the four periods for each item of PHQ-9 and GAD-7 (Table 2).

Based on analysis of the trend of each item, most statuses of the PHQ-9 (Q1, Q2, Q4, Q5, Q6, Q7, and Q9) and GAD-7 (Q1, Q3, Q4, Q6, Q7) improved at the 6month follow-up. However, insomnia (PHQ-9 Q3) and feeling fidgety or restless (PHQ-9 Q8) were still disturbing the patients at 6 months (Fig. 3). Compared with the status of depression and anxiety between the pretreatment and post-treatment periods, the degrees of depression and anxiety improved in 27 patients (19.71\%) and 26 patients (18.98\%), respectively. On the contrary, 7 patients $(5.11 \%)$ and 11 patients (8.03\%) showed worsened depression and anxiety status (Table 3). The changes of PHQ-9 and GAD-7 score in each patient are shown in supplementary Figure 4.

\section{Discussion}

The treatment process of various malignant tumors occasionally results in anxiety or depression in cancer survivors, from diagnosis to surveillance [20]. The PHQ-9 and GAD-7, which are well-validated, are the most commonly used measures for the objective assessment of depression and anxiety, respectively [11, 14, 17, 20, 21]. In recent study, the authors evaluated changes in depression and anxiety during treatment and the short-term follow-up period in patients with breast cancer. Although the degree of depression and anxiety was maintained or increased during breast cancer treatment, it decreased during the 6month follow-up period after surgery than during the treatment period. This could be the reason why physicians and caregivers need to continuously support patients with breast cancer regarding their mental problems and stress during treatment. There were significant differences during the four periods, including preoperative, postoperative, post-treatment, and 6-month follow-up periods, and the

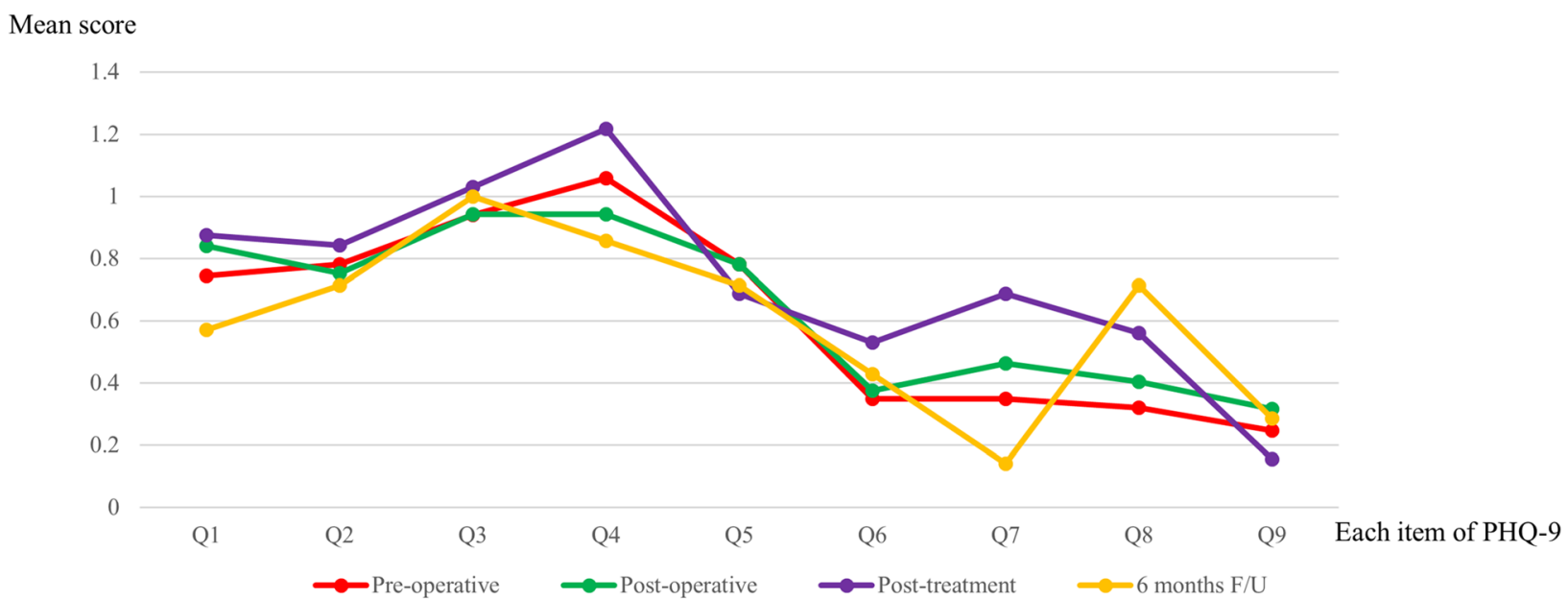

Mean score

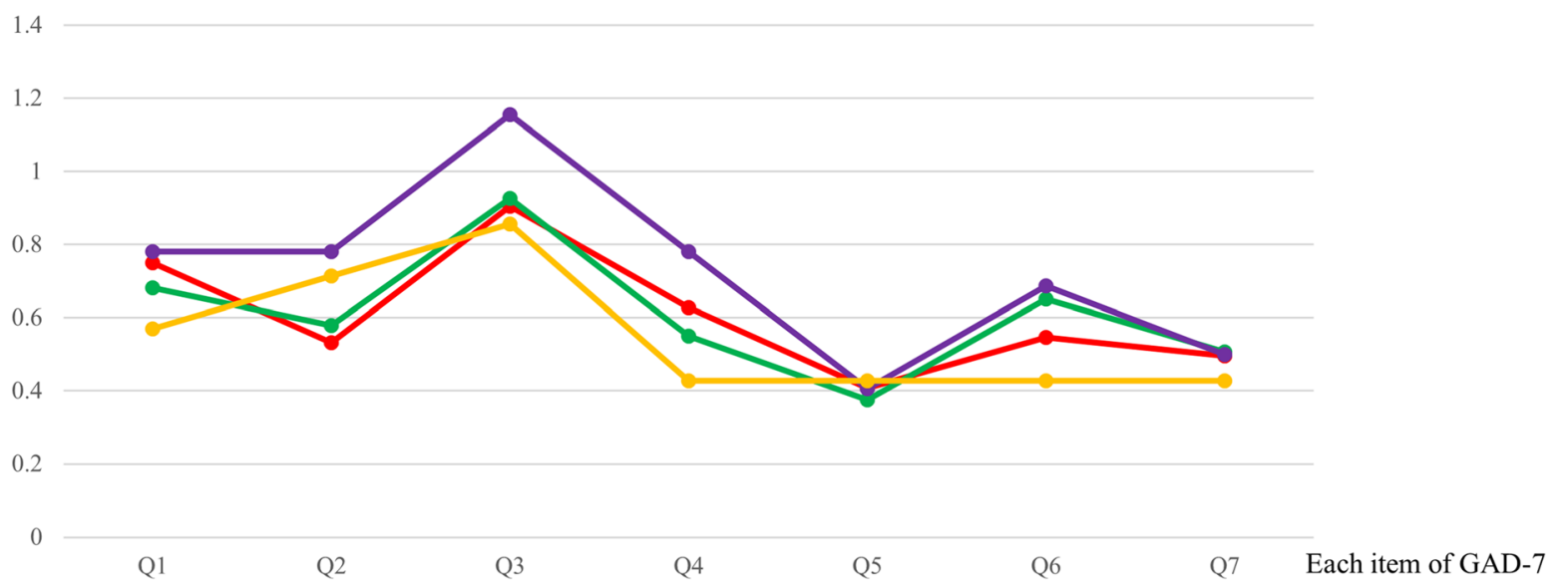

Fig. 2 Mean scores of each item on the PHQ-9 (a) and GAD-7 (b) 
Table 2 Statistical differences among four periods in each item of PHQ-9 and GAD-7

\begin{tabular}{|c|c|c|c|c|c|}
\hline PHQ-9 & Preoperative & Postoperative & Post-treatment & 6 months after surgery & $p$-value \\
\hline Q1. Little interest or pleasure in doing things? & $0.75 \pm 0.96$ & $0.84 \pm 0.78$ & $0.88 \pm 0.94$ & $0.57 \pm 0.49$ & 0.739 \\
\hline Q2. Feeling down, depressed, or hopeless? & $0.79 \pm 0.87$ & $0.75 \pm 0.77$ & $0.84 \pm 0.85$ & $0.71 \pm 0.70$ & 0.961 \\
\hline Q3. Trouble falling or staying asleep or sleeping too much? & $0.96 \pm 1.00$ & $0.94 \pm 0.92$ & $1.03 \pm 1.09$ & $1.00 \pm 1.07$ & 0.971 \\
\hline Q4. Feeling tired or having little energy? & $1.08 \pm 1.02$ & $0.94 \pm 0.86$ & $1.22 \pm 0.87$ & $0.86 \pm 0.99$ & 0.546 \\
\hline Q5. Poor appetite or overeating? & $0.81 \pm 0.95$ & $0.78 \pm 0.87$ & $0.69 \pm 0.82$ & $0.71 \pm 0.88$ & 0.957 \\
\hline $\begin{array}{l}\text { Q6. Feeling bad about yourself or that you are a failure or have } \\
\text { let yourself or your family down? }\end{array}$ & $0.39 \pm 0.07$ & $0.38 \pm 0.67$ & $0.53 \pm 0.76$ & $0.43 \pm 1.05$ & 0.638 \\
\hline $\begin{array}{l}\text { Q7. Trouble concentrating on things, such as reading the } \\
\text { newspaper or watching television? }\end{array}$ & $0.66 \pm 0.40$ & $0.46 \pm 0.65$ & $0.69 \pm 0.93$ & $0.14 \pm 0.35$ & 0.060 \\
\hline $\begin{array}{l}\text { Q8. Moving or speaking so slowly that other people could } \\
\text { have noticed? Or so fidgety or restless that you have been } \\
\text { moving a lot more than usual? }\end{array}$ & $0.38 \pm 0.74$ & $0.41 \pm 0.69$ & $0.56 \pm 0.84$ & $0.71 \pm 1.03$ & 0.246 \\
\hline $\begin{array}{l}\text { Q9. Thoughts that you would be better off dead or thoughts } \\
\text { of hurting yourself in some way? }\end{array}$ & $0.31 \pm 0.63$ & $0.32 \pm 0.65$ & $0.16 \pm 0.45$ & $0.29 \pm 0.70$ & 0.664 \\
\hline \multicolumn{6}{|l|}{ GAD-7 } \\
\hline Q1. Feeling nervous, anxious, or on edge & $0.75 \pm 0.76$ & $0.68 \pm 0.68$ & $0.78 \pm 0.79$ & $0.57 \pm 1.05$ & 0.833 \\
\hline Q2. unable to stop or control worrying & $0.53 \pm 0.75$ & $0.58 \pm 0.74$ & $0.78 \pm 0.83$ & $0.71 \pm 1.03$ & 0.405 \\
\hline Q3. Worrying too much about different things & $0.91 \pm 0.84$ & $0.93 \pm 0.81$ & $1.16 \pm 0.95$ & $0.86 \pm 0.99$ & 0.502 \\
\hline Q4. Trouble relaxing & $0.63 \pm 0.84$ & $0.55 \pm 0.80$ & $0.78 \pm 0.87$ & $0.43 \pm 0.73$ & 0.559 \\
\hline Q5. Being so restless that it is hard to sit still & $0.41 \pm 0.76$ & $0.38 \pm 0.60$ & $0.41 \pm 0.56$ & $0.43 \pm 0.73$ & 0.990 \\
\hline Q6. Becoming easily annoyed or irritable & $0.55 \pm 0.80$ & $0.65 \pm 0.84$ & $0.69 \pm 0.78$ & $0.43 \pm 1.05$ & 0.686 \\
\hline Q7. Feeling afraid as if something awful might happen & $0.50 \pm 0.75$ & $0.51 \pm 0.68$ & $0.50 \pm 0.72$ & $0.43 \pm 0.73$ & 0.995 \\
\hline
\end{tabular}

degree of depression was significantly higher at the immediate post-treatment period than during the postoperative and 6-month follow-up period.

Regarding each question in PHQ-9 and GAD-7, the Q3 (trouble falling or staying asleep, or sleeping too much?) and Q4 (feeling tired or having little energy?) of PHQ-9 and Q3 (worrying too much about different things) of GAD-7 showed highest mean scores for all four periods. At the 6-month follow-up, the treatments were exhausted, except hormone treatment, and most factors had improved, including depression and anxiety. However, the sleep disturbance (Q3) of PHQ-9 was determined to be the most severe and persisting problem until 6 months after the completion of breast cancer treatment and worrying about many things (Q3) of GAD-7 persisted with higher scores in every time period, although Burgess et al. reported that the prevalence of depression, anxiety, or both decreases and the survival period passes [8].

For accurate evaluation of patients' mental health status, it is more effective when the test questionnaires are answered by the patients themselves because of its reliability, objectiveness, and accuracy. However, the patients' burden, such as long repeated work or too long sentences, has been indicated as a reason for noncompliance. The elderly or sicker population showed lower compliance than the healthier population [22-26]. Although many studies have measured depression and anxiety in patients with breast cancer at a specific treatment or time point, only few studies have used continuous follow-up tests [8, 27]. The authors conducted a serial assessment, which was performed using the ePRO platform for depressive mood and anxiety in patients with breast cancer during treatment and short-term follow-up periods. We found that the depressive mood and anxiety gradually increased and improved when the treatments are over.

The main limitation of this study was that we were unable to evaluate the degree of depression and anxiety at the time of each treatment, such as chemotherapy and radiotherapy. Although Nakamura et al. [23] reported that chemotherapy has a decisive effect on depression and anxiety in patients with breast cancer, we could not assess this effect at each time points because the chemotherapy and radiotherapy were performed in other departments based on the multidisciplinary clinical system. And we performed the study with only small population and did not consider the effects of each treatment on mental health status. Furthermore, we did not conduct the analysis for within-individual comparison. However, we conducted this study using a web-based system for patients with breast cancer amd assessed depression and anxiety at least 
A

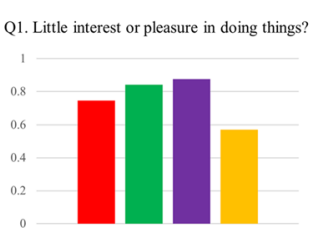

Q4. Feeling tired or having little energy?

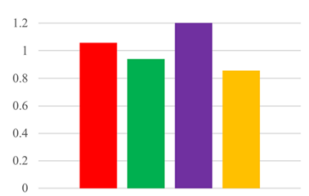

Q7. Trouble concentrating on things, such as reading the newspaper or watching television?

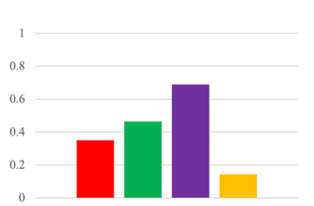

B

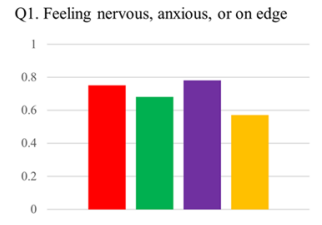

Q4. Trouble relaxing

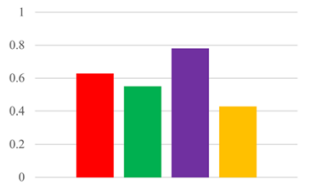

Q7. Feeling afraid as if something awful might happen

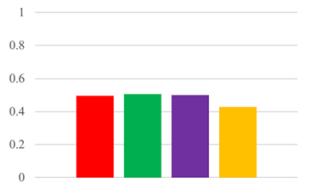

Fig. 3 Scores of each item on the PHQ-9 (a) and GAD-7 (b). Most of the specific symptoms were improved at the 6-month follow-up period. All contents of the system were originally written in Korean
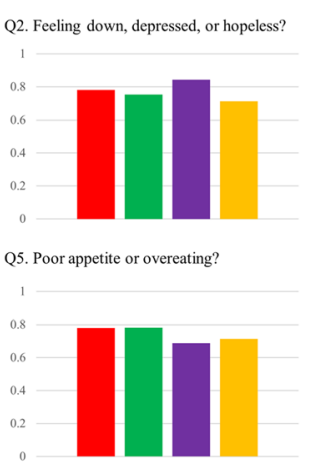

Q8. Moving or speaking so slowly that other people could have noticed? Or so fidgety or restless that you have been moving a lot more than usual?
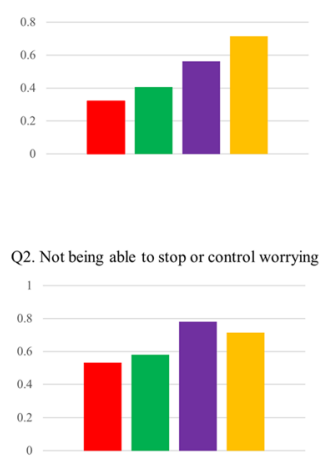

Q5. Being so restless that it's hard to sit still

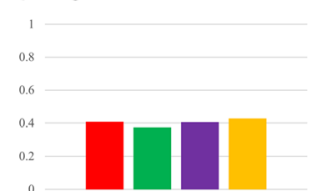

Q3. Worrying too much about different things

Q6. Becoming easily annoyed or irritable

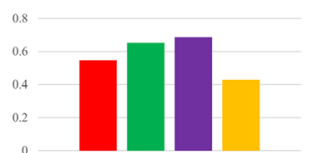

Q5. Poor appetite or overeating?

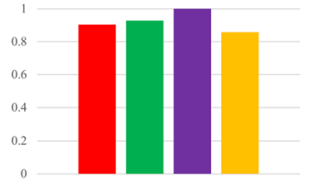

Table 3 Degree of depression and anxiety in pretreatment and post-treatment states for breast cancer

\begin{tabular}{|c|c|c|c|c|c|c|c|c|c|c|c|c|}
\hline & & & \multicolumn{10}{|c|}{ Pretreatment state } \\
\hline & & & \multicolumn{4}{|c|}{ Depression } & & & \multicolumn{4}{|l|}{ Anxiety } \\
\hline & & & No & Mild & Moderate & Severe & & & No & Mild & Moderate & Severe \\
\hline \multirow{4}{*}{$\begin{array}{l}\text { Post-treatment } \\
\text { state }\end{array}$} & \multirow[t]{4}{*}{ Depression } & No & $66(48.18)$ & $21(15.33)$ & $2(1.46)$ & - & Anxiety & No & $75(54.75)$ & $20(14.6)$ & $4(2.92)$ & - \\
\hline & & Mild & $4(2.92)$ & $18(13.14)$ & $3(2.19)$ & $1(0.73)$ & & Mild & $7(5.11)$ & $9(6.57)$ & $1(0.73)$ & - \\
\hline & & Moderate & - & $3(2.19)$ & $11(8.03)$ & $7(5.11)$ & & Moderate & $1(0.73)$ & $3(2.19)$ & $5(3.65)$ & $1(0.73)$ \\
\hline & & Severe & - & - & - & $1(0.73)$ & & Severe & $2(1.46)$ & $2(1.46)$ & $3(2.19)$ & $4(2.92)$ \\
\hline Improved & & \multicolumn{5}{|l|}{$34(24.82)$} & \multicolumn{6}{|c|}{$26(18.98)$} \\
\hline Worsen & & \multicolumn{5}{|l|}{$7(5.11)$} & \multicolumn{6}{|c|}{$18(13.14)$} \\
\hline
\end{tabular}

"Data are expressed as $n, \%$ 
four consecutive times in patients with breast cancer. Clinging to the classical method of assessment without considering the characteristics of modern patients degrades the reliability and accuracy of the tests. Furthermore, it would be unreasonable to reach a conclusion regarding a patient's mental health status using the result of only a single test point. Therefore, for more accurate evaluation of the mental health status of patients with breast cancer, further serial assessment of depression and anxiety is necessary using a more accessible system, and it may lead to an improvement in their quality of life.

\section{Conclusion}

According to the short-term serial assessment of depression and anxiety, most factors associated with depression and anxiety improved after treatment. However, sleep disturbance and worrying about several things persisted with higher scores at every time period, even at the 6month follow-up. Therefore, patients with breast cancer should be evaluated for depression and anxiety continuously as well as during the treatment period, and patients and physicians should work together to actively manage them.

\section{Abbreviations}

PRO: Patient-reported outcome; ePRO: electronic patient-reported outcome; PHQ-9: Patient Health Questionnaire 9-item depression scale; GAD-

7: Generalized Anxiety Disorder scale (GAD-7)

\section{Supplementary Information}

The online version contains supplementary material available at https://doi. org/10.1186/s12885-021-08771-y.

Additional file 1: Supple Figure 1. Flow chart of the electronic patient-reported outcome (ePRO) of the PHQ-9 and GAD-7 in breast cancer.

Additional file 2: Supple Figure 2. Patient list from the electronic patient-reported outcome (ePRO) of anxiety and depressive symptoms for patients with breast cancer. The severity of each item in the PHQ-9 and GAD-7 is expressed in degrees of green and pink colors, respectively.

Additional file 3: Supple Figure 3. Correlation graphs between depression and anxiety as a quartile, one-dimensional correlation, and a heat map-style graph.

Additional file 4

\section{Acknowledgements}

Not Applicable.

\section{Authors' contributions}

HYP and $J$ contributed to the study design and manuscript writing. $J J H_{\text {, }}$ WWK, and BJK conducted the literature research. JMW, HDR, and GK developed the electronic platform for this study. Data acquisition and analysis were conducted by JL. YSC and SJL reviewed the manuscript and made revisions. All authors read and approved the final manuscript. WKL performed statistical re-analysis for revision of this manuscript.

\section{Funding}

This work was supported by the National Research Foundation of Korea (NRF) grant funded by the Korea government (NRF-2019R1A2C1006264 2019R1F1A1063853) and this work was supported by the National Research
Foundation of Korea (NRF) grant funded by the Korea government (2017M3A9G8083382).

Availability of data and materials

The data sets generated and/or analyzed in this study are not publicly available. However, they are available from the corresponding author upon reasonable request.

\section{Declarations}

Ethics approval and consent to participate

All procedures performed in studies involving human participants were in accordance with the ethical standards of the institutional and/or national research committee and with the 1964 Helsinki declaration and its later amendments or comparable ethical standards. The ethical approval for the study was obtained from Institutional Review Board of the KNUCH (KNUCH 2020-06-029-001). Informed consent was obtained from all individual participants included in the study.

\section{Consent for publication}

Not Applicable.

\section{Competing interests}

The authors declare that they have no conflict of interest.

\section{Author details}

${ }^{1}$ Department of Surgery, School of Medicine, Kyungpook National University, Kyungpook National University Chilgok Hospital, Daegu 41404, Republic of Korea. ${ }^{2}$ Department of Psychiatry, School of Medicine, Kyungpook National University, Kyungpook National University Hospital, Daegu, Republic of Korea. ${ }^{3}$ Department of Oncology/Hematology, School of Medicine, Kyungpook National University, Kyungpook National University Chilgok Hospital, Daegu, Republic of Korea. ${ }^{4}$ Clupea, Inc., Daegu, Republic of Korea. ${ }^{5}$ Department of Medical Informatics, School of Medicine, KyungPook National University, Daegu, Republic of Korea.

Received: 10 March 2021 Accepted: 7 September 2021

Published online: 29 September 2021

\section{References}

1. Bray F, Ferlay J, Soerjomataram I, Siegel RL, Torre LA, Jemal A. Global cancer statistics 2018: GLOBOCAN estimates of incidence and mortality worldwide for 36 cancers in 185 countries. CA Cancer J Clin. 2018:68(6):394-424. https://doi.org/10.3322/caac.21492.

2. Ganz PA, Kwan L, Stanton AL, Krupnick JL, Rowland JH, Meyerowitz BE, et al. Quality of life at the end of primary treatment of breast cancer: first results from the moving beyond cancer randomized trial. J Natl Cancer Inst. 2004; 96(5):376-87. https://doi.org/10.1093/jnci/djh060.

3. Deshields T, Tibbs T, Fan MY, Taylor M. Differences in patterns of depression after treatment for breast cancer. Psycho-Oncology. 2006;15(5):398-406. https://doi.org/10.1002/pon.962.

4. Linden W, Vodermaier A, Mackenzie R, Greig D. Anxiety and depression after cancer diagnosis: prevalence rates by cancer type, gender, and age. J Affect Disord. 2012;141(2-3):343-51. https://doi.org/10.1016/j.jad.2012.03.025.

5. DiMatteo MR, Lepper HS, Croghan TW. Depression is a risk factor for noncompliance with medical treatment: meta-analysis of the effects of anxiety and depression on patient adherence. Arch Intern Med. 2000; 160(14):2101-7. https://doi.org/10.1001/archinte.160.14.2101.

6. Luber MP, Meyers BS, Williams-Russo PG, Hollenberg JP, DiDomenico TN, Charlson ME, et al. Depression and service utilization in elderly primary care patients. Am J Geriatr Psychiatry. 2001;9(2):169-76. https://doi.org/10.1097/ 00019442-200105000-00009.

7. Lang-Rollin I, Berberich G. Psycho-oncology. Dialogues Clin Neurosci. 2018; 20(1):13-22. https://doi.org/10.31887/DCNS.2018.20.1/ilangrollin.

8. Burgess C, Cornelius V, Love S, Graham J, Richards M, Ramirez A. Depression and anxiety in women with early breast cancer: five year observational cohort study. BMJ. 2005:330(7493):702.

9. Bennett AV, Jensen RE, Basch E. Electronic patient-reported outcome systems in oncology clinical practice. CA Cancer J Clin. 2012;62(5):337-47. https://doi.org/10.3322/caac.21150. 
10. Kroenke K, Spitzer RL, Williams JB. The PHQ-9: validity of a brief depression severity measure. J Gen Intern Med. 2001;16(9):606-13. https://doi.org/10.1 046/j.1525-1497.2001.016009606.x.

11. Spitzer RL, Kroenke K, Williams JB, Löwe B. A brief measure for assessing generalized anxiety disorder: the GAD-7. Arch Intern Med. 2006;166(10): 1092-7. https://doi.org/10.1001/archinte.166.10.1092.

12. Hinz A, Mehnert A, Kocalevent RD, Brähler E, Forkmann T, Singer S, et al. Assessment of depression severity with the PHQ-9 in cancer patients and in the general population. BMC Psychiatry. 2016;16(1):22. https://doi.org/10.11 86/s12888-016-0728-6.

13. Watzke B, Heddaeus D, Steinmann M, König HH, Wegscheider K, Schulz H, et al. Effectiveness and cost-effectiveness of a guideline-based stepped care model for patients with depression: study protocol of a cluster-randomized controlled trial in routine care. BMC Psychiatry. 2014;14(1):230. https://doi. org/10.1186/s12888-014-0230-y.

14. Martin A, Rief W, Klaiberg A, Braehler E. Validity of the brief patient health questionnaire mood scale (PHQ-9) in the general population. Gen Hosp Psychiatry. 2006;28(1):71-7. https://doi.org/10.1016/j.genhosppsych.2005.07.003.

15. Wittkampf KA, Naeije L, Schene AH, Huyser J, van Weert HC. Diagnostic accuracy of the mood module of the patient health questionnaire: a systematic review. Gen Hosp Psychiatry. 2007;29(5):388-95. https://doi.org/1 0.1016/j.genhosppsych.2007.06.004.

16. Thekkumpurath P, Walker J, Butcher I, Hodges L, Kleiboer A, O'Connor M, et al. Screening for major depression in cancer outpatients: the diagnostic accuracy of the 9-item patient health questionnaire. Cancer. 2011;117(1): 218-27. https://doi.org/10.1002/cncr.25514.

17. Löwe B, Decker O, Müller S, Brähler E, Schellberg D, Herzog W, et al. Validation and standardization of the generalized anxiety disorder screener (GAD-7) in the general population. Med Care. 2008;46(3):266-74. https://doi. org/10.1097/MLR.0b013e318160d093.

18. Kroenke K, Spitzer RL, Williams JB, Löwe B. The patient health questionnaire somatic, anxiety, and depressive symptom scales: a systematic review. Gen Hosp Psychiatry. 2010;32(4):345-59. https://doi.org/10.1016/j.genhosppsych.2 010.03.006.

19. Mossman SA, Luft MJ, Schroeder HK, Varney ST, Fleck DE, Barzman DH, et al. The Generalized Anxiety Disorder 7-item scale in adolescents with generalized anxiety disorder: Signal detection and validation. Ann Clin Psychiatry. 2017;29(4):227-234a.

20. Yi JC, Syrjala KL. Anxiety and depression in Cancer survivors. Med Clin North Am. 2017;101(6):1099-113. https://doi.org/10.1016/j.mcna.2017.06.005.

21. Kroenke K, Wu J, Yu Z, Bair MJ, Kean J, Stump T, et al. Patient health questionnaire anxiety and depression scale: initial validation in three clinical trials. Psychosom Med. 2016;78(6):716-27. https://doi.org/10.1097/PSY. 0000000000000322

22. Atherton PJ, Burger KN, Pederson LD, Kaggal S, Sloan JA. Patient-reported outcomes questionnaire compliance in Cancer cooperative group trials (Alliance N0992). Clin Trials. 2016;13(6):612-20. https://doi.org/10.1177/174 0774516655101

23. Rolstad S, Adler J, Rydén A. Response burden and questionnaire length: is shorter better? A review and meta-analysis. Value Health. 2011;14(8):1101-8. https://doi.org/10.1016/j.jval.2011.06.003.

24. Sloan JA, Berk L, Roscoe J, Fisch MJ, Shaw EG, Wyatt G, et al. Integrating patient-reported outcomes into cancer symptom management clinical trials supported by the National Cancer Institute-sponsored clinical trials networks. J Clin Oncol. 2007;25(32):5070-7. https://doi.org/10.1200/JCO.2 007.12.7670.

25. Basch E, Deal AM, Kris MG, Scher HI, Hudis CA, Sabbatini P, et al. Symptom monitoring with patient-reported outcomes during routine Cancer treatment: a randomized controlled trial. J Clin Oncol. 2016;34(6):557-65. https://doi.org/10.1200/JCO.2015.63.0830.

26. Sim YSG, Son BH, Ahn SH, Lee JW, Shin YW. Measurement of depression in breast Cancer patients by using a Mobile application : a feasibility and reliability study. J Korean Neuropsychiatric Assoc. 2016;55(3):234-44. https:// doi.org/10.4306/jknpa.2016.55.3.234.

27. Nakamura ZM, Deal AM, Nyrop KA, Chen YT, Quillen LJ, Brenizer T, et al. Serial assessment of depression and anxiety by patients and providers in women receiving chemotherapy for early breast cancer. Oncologist. 2020;26:147-56.

\section{Publisher's Note}

Springer Nature remains neutral with regard to jurisdictional claims in published maps and institutional affiliations.

Ready to submit your research? Choose BMC and benefit from:

- fast, convenient online submission

- thorough peer review by experienced researchers in your field

- rapid publication on acceptance

- support for research data, including large and complex data types

- gold Open Access which fosters wider collaboration and increased citations

- maximum visibility for your research: over $100 \mathrm{M}$ website views per year

At BMC, research is always in progress.

Learn more biomedcentral.com/submissions 